\title{
The Psychosomatic Concept of "Intranatal Inward Orientation" (IIO) as a Background Mode of Experience in the Birthing Process: A Scale Development Study with 73 First-Time Mothers
}

\author{
Werner Stadlmayr 1,2,3*, Daniela Bielinski-Blattmann",4, Sakari Lemola4, Kai von Klitzing5,6, \\ Heidi Simoni ${ }^{5,7}$, Felix Amsler', Daniel Surbek², Johannes Bitzer9 \\ ${ }^{1}$ Department of Obstetrics and Gynaecology, Kantonsspital, Aarau, Switzerland \\ ${ }^{2}$ Department of Obstetrics and Gynaecology, University Hospital, Bern, Switzerland \\ ${ }^{3}$ Department of Clinical Research, University of Bern, Bern, Switzerland \\ ${ }^{4}$ Department of Psychology, University of Basel, Basel, Switzerland \\ ${ }^{5}$ Department of Child and Adolescent Psychiatry, University Hospital, Basel, Switzerland \\ ${ }^{6}$ Department of Child and Adolescent Psychiatry, University Hospital, Leipzig, Germany \\ ${ }^{7}$ Marie Meierhofer Institut für das Kind, Zürich, Switzerland \\ ${ }^{8}$ Amsler Consulting, Basel, Switzerland \\ ${ }^{9}$ Department of Obstetrics and Gynaecology, University Hospital, Basel, Switzerland \\ Email: ${ }^{*}$ wstadlmayr@gmx.com
}

Received 18 March 2014; revised 20 April 2014; accepted 30 April 2014

Copyright (C) 2014 by authors and OALib.

This work is licensed under the Creative Commons Attribution International License (CC BY).

http://creativecommons.org/licenses/by/4.0/

(c) (i) Open Access

\section{Abstract}

Objective: In order to describe maternal intranatal processes from a common psychosomatic perspective, the clinical notion of "intranatal regression" or "intranatal psychophysical withdrawal" was presented. However, this idea of an underlying mode of experience pervading the birthing process has never been explored systematically. We further elaborated on this notion by introducing the concept of Intranatal Inward Orientation (IIO), supporting a psychosomatic approach in modern obstetrics. Methods: 73 first-time mothers were interviewed 3 - 4 days postpartum. IIO was evaluated on four axes of perceptions: a changing sense 1) of time, 2) of space, 3) of attachment, and 4) a change in the predominant communication style with significant others (partners, midwives). In addition, other subjective variables (questionnaires) and obstetric variables were assessed. Results: A one-factor solution (Eigen-value of $\mathbf{> 1 . 0}$ ) provides firm statistical support for

\footnotetext{
${ }^{*}$ Corresponding author.
} 
IIO as a consistently integrated scale (C'alpha 0.74). Inter-rater reliability is very good (Intraclass correlation 0.83). IIO is independent of other subjective qualities, like anxiety, coping, and control. IIO is correlated with fewer epidural blocks. Likewise high IIO is more frequently associated with a low birth complication profile (spontaneous delivery, not longer than 12 hours, no oxytocin for augmentation of labour, and no epidural block). Conclusion: IIO is a promising psychosomatic concept. It supports the idea of a psychological, relationship- and interaction-oriented approach to promote more natural childbirth. It may also lead to a better understanding of the emerging of a traumatic birth experience. Further elaboration of the concept is recommended.

\section{Keywords}

Birth Experience, Psychosomatic Theory, Intranatal Inward Orientation, Intranatal Dissociation, Mode of Experience

\section{Introduction}

Psychosomatic approaches in medicine globally deal with questions on 1) how somatic processes affect psychological dynamics, for instance in life-threatening situations or after certain surgical procedures implying changes in the body image, and 2) what developmental processes are affected in the context of certain somatic changes, e.g. in the transition to menopause; less frequent are 3) approaches in which the effects of psychological dynamics on somatic processes or systems are investigated, as e.g. in psycho-immunology and psycho-cardiology. Applying the latter perspective of psychosomatics to obstetrics, the somatic field of interest of our work group, leads to the question whether childbirth-promoting psychological processes during delivery do exist, and if so, how they may affect obstetric processes. Accordingly, this paper will primarily deal with the description of psychological (perceptional and interactional) dynamics and their interference with the somatic process of giving birth.

Although it is often acknowledged that "working towards optimum safety in childbirth must mean increasing the rate of uncomplicated vaginal delivery" [1], ways to achieve this goal in the face of peak obstetric intervention rates are less clear. One way may be to look more closely at psychosomatic aspects of the birth process. In this paper, we focus on an integrated view of maternal perceptional and experiential changes during childbirth, which we summarize in a new concept, labelled "Intranatal Inward Orientation" (IIO). We then compare IIO with other subjective perceptions and experiences during childbirth, and explore its associations with objective, i.e. observable, childbirth-related variables.

Phenomena involving intranatal changes in perception and experience have rarely been described systematically in the research literature. In the introduction to her work on "temporal and spatial experience of multiparous women during labour", Rich [2] states that "there seem to be behavioural cues which suggest that the psychodynamic process experienced simultaneously with the physiological process has unique and extraordinary qualities for the woman in labour". She suggests that interaction and behaviour, as well as the experience of time and space are affected by this process.

\subsection{A Common Perspective on Perceptional Changes during Labour-Intranatal Inward Orientation (IIO)}

Understanding these experiential changes as an integrated phenomenon, in contrast to isolated perceptions, means developing a meta-perspective, as described in the German-language literature by the concept of "intranatal regression" (Ger: Intrapartale Regression [3]), relabelled "intranatal psychophysical withdrawal" by Stauber [4] (Ger: Intrapartaler psychophysischer Rückzug). This understanding of the physiological birthing process implies a change from an outwards directed, cognitively controlling attitude towards an introspective state of mind, characterized by acceptance and dedication, hypothesizing the evolution of a new psychophysical state and concretely referred to as "regression" and "withdrawal".

To elucidate this concept, we refer to Spitz [5], describing a healthy individual's two fundamental psycho- 
physical states, which are characterized by two modes of experience, each implying a specific psychosomatic organization of the body-mind unit. Spitz distinguishes a sensory or diacritic mode of experience from an emotive or coenesthetic mode. While diacritic perception generally relates to an awareness that clearly differentiates surrounding objects, the coenesthetic mode of experience refers rather to a daydream-like awareness in which orientation in the environment is assured by sensations instead of sensory perceptions. Intranatal "regression" and "withdrawal" correspond to this latter mode of experience, i.e. the psychophysical state reached in the course of a process, we have re-labelled "intranatal inward orientation" (IIO). We understand the daydream-like aspect of this mode of experience as a dissociative quality, which in adults is mainly characterized by absorption as well as derealisation [6] [7].

Thus, our understanding of IIO is in line with the idea of normative, non-pathological dissociative phenomena, not induced by trauma [8]. The birth process often induces normative dissociative dynamics described phenolmenologically as "spacing out" or feeling "entranced" [9].

We quote from a parturient's experience [9] to illustrate non-pathological alterations occurring during the birthing process: "When I had the baby, I thought it had only been 2 hours since I had been admitted to the hospital. I had no idea that it had been over 12 hours, almost 18 hours, between the time I had arrived and the time I had delivered. When I looked at the baby's bracelet the next morning and it said 9:10, I at first thought I had delivered at 9:10 am but when I saw 9:10 pm, I called the nurse in. I said to her, "is this an error?" She said "no" and looked at me like "I was absolutely nuts!"

Following Rich [2] and Beck [10], we operationalize this aspect of IIO in two sub-dimensions: a changing sense of time, and a changing sense of space. In addition to these perceptional changes linked with normative dissociation, the model described by Spitz [5] implies varying patterns of attachment and communication. In the emotive (or so-called coenesthetic) mode, one person generally depends on affective and non-verbal communication with the other, who needs to be present within arm's length. In contrast, when sensory (or so-called diacritic) orientation is predominant, others are contacted by means of cognitive and verbal exchange. These two aspects are operationalized in IIO by two further sub-dimensions: a changing sense of attachment and a shift in the pre-dominant communication style. (To elucidate the significance and variance of communication in labour, see [11] (communication by “touch"), [12] (communication by “sound"), [13] [14] (perception of "communication”)).

IIO as a meta-concept needs to be distinguished from other basic intranatal experiential qualities, like 1) pain and 2) exhaustion [15]-[17], sometimes combined in one dimension as physical discomfort [18] [19], 3) anxiety [20] [21], often assessed with respect to labour pain [22]-[27], 4) dominance of bodily processes (DbodP), a basic dimension referring to the intensive experience of the rhythm and power of labour contractions [28], both of which are different from the mere experience of pain alone, and 5) the experience of control, understood as a multidimensional concept [29] describing the experience of being the "subject instead of the object" in a situation [30] in contrast to concepts focusing exclusively on limited aspects of external control like "decision-making" [31] or "information-providing". Finally, another intranatal experiential quality of major significance is 6) coping, traditionally investigated as "coping with pain" [32]. However, there are two more sub-dimensions: "hopelessness vs. confidence" [33] [34] and "fearful control vs. acceptance (letting-go)" [3], which means that in addition to coping techniques, like breathing and relaxation, emotions and attitudes also have to be taken into account [35]-[37] when exploring intranatal coping processes.

\subsection{Summary and Research Questions}

Intranatal Inward Orientation (IIO) is understood as a theoretical construct that integrates intranatal experiential and perceptional changes (time and space, attachment and communication) from a common perspective. It is characterized by a change in the predominant internal processing program or set of programs. This goes along with a new mode of experience, described as a "coenesthetic" psychosomatic organization [5].

In order to elicit the potential of IIO as a clinical concept our study focuses on the following questions:

1) Can Intranatal Inward Orientation IIO be reliably operationalized and assessed by different raters in interviews?

2) How is IIO associated with the other intranatal subjective experiences?

3) How is IIO associated with somatic birth variables as well as the overall childbirth complication profile? 


\section{Method}

\subsection{Study Design and Study Sample}

The study was approved by the local ethical committee as part of a long-term study evaluating family development. Inclusion criteria were appropriate language knowledge (German), prenatal agreement to participate, and primiparity. Participants were recruited over a 19-month period: As, due to 1) late hospital admission immediately before delivery and 2) limited recruitment staff; only about $50 \%$ of the eligible women were approached (n $=320$ ), and as out of these only $80(25 \%)$ agreed to participate; the study was finally performed in a convenience sample. Of the participants, 27 (33.8\%) experienced difficult pregnancies, which is partly due to the specialization of the hospital.

Of the participating 80 women (mean age 30.8 years ranging from 15.8 to 43.1 years), 76 (94\%) were accompanied by a partner. In 33 (41.2\%), an epidural block was applied, i.e. a so-called regional anaesthesia restricted to the lower body and limbs making them mostly insensitive to pain, but also not infrequently affecting motor capacity, preventing women from moving around or squatting during labour. The distribution of the mode of delivery was as follows: 48 (60.0\%) spontaneous, 19 (23.8\%) assisted, 4 (5.0\%) elective caesarean section and 9 (11.2\%) unplanned caesarean section. These percentages are comparable to the usual rates at that hospital among primiparous women for the years 1997 and 1998. There were 13 (16.3\%) preterm deliveries before week 37 (no neonatal deaths). In 10 infants (12.5\%) the birth weight was below 2500 grams (1/1.15\%, below 1000 grams).

Basic psychodiagnostic and sociodemographic data were assessed prenatally in 75 (93.8\%) women: educational level was low/lower middle 31\%, middle 26\%, and upper middle/upper $42 \%$. The Revised Symptom Checklist [38] [39] showed psychiatric disorders in 27 participants, which is in line with a normative group [39]. After birth, three participants refused to do the postnatal interview. In all but one case the interviews were done between 48 and 96 hours after birth. Excluding the four women with an elective caesarean, we finally analysed 73 participants.

\subsection{Statistical Analysis (SPSS 16.0)}

To construct scales we used factor analysis (principal component analysis with varimax rotation).

Dimensions are considered to be sufficiently independent with an inter-scale correlation of below 0.55 to 0.70 [40]. Inter-rater reliability was assessed by intraclass correlation coefficients (ICC) of the one-way random effect model and classified as follows: an ICC $>0.75$ is considered "very good", between 0.75 and 0.40 "good" to "satisfactory", and $<0.40$ "unsatisfactory" [41].

To test associations Pearson correlations were used for metrically scaled and Spearman correlations for ordinally scaled variables. IIO was also dichotomized (high/low) on the basis of a cluster analysis (log-likelihood distance measure with Schwarz's Bayesian criterion). Furthermore, we performed student t-tests, chi-square tests, and Mann-Whitney U-tests.

\subsection{Obstetric Measures}

Obstetric variables were collected from the patients' records: induction (i.e. the use of medication to induce labour), augmentation (i.e. substances to intensify insufficient contractions once the labour process has begun), epidural block (i.e. an anaesthesia making the lower body insensitive to pain), infant's birth weight, duration of labour, and mode of delivery (spontaneous, i.e. with no further assistance at the moment of birth; vaginally assisted by vacuum or forceps extraction, elective (so-called primary) caesarean section before the beginning of labour, or a so-called secondary caesarean section after the labour process has already begun). Based on clinical assumptions we defined three birth complication profiles: 1) low complication profile, i.e. spontaneous, no augmentation, no epidural block, labour $<12$ h; 2) moderate complication profile, i.e. spontaneous, no epidural block, labour $>12 \mathrm{~h}$ or vaginal-assisted and/or epidural block, labour $<12 \mathrm{~h}$; 3) high complication profile, i.e. vaginal-assisted and/or epidural block, labour $>12 \mathrm{~h}$ or unplanned caesarean section.

\subsection{The Berne-Basle Childbirth Interview and the Dimensions Used in This Analysis}

The interview technique: All interviews were performed by the same male researcher, who is an experienced 
clinical obstetrician and a psychoanalytically trained psychotherapist. The basic idea of the semi-structured interview was to allow the interviewee to enter a narrative process integrating all the aspects of birth and delivery. The style was open, allowing a free flow of the participants' thoughts, and also allowing the participants to remain with the description of their current state as well as with possible concerns about the future; however, the interviewee's flow of ideas was also assisted by associative questions, if the new mother could not think of any (more) aspects or details concerning the subjects already focused on. The interviewer carefully monitored the interviewee's as well as his own emotional response. In order to maintain continuity in the narrative process and to avoid a possible premature end of the interview due to heightened discomfort or stress on the part of the interviewee, she was encouraged to find ways to carefully describe body sensations or behavioural dynamics. The participants were also assured that negative comments about caregivers would be kept confidential as would any other information given in the interview and would be recorded solely for the purposes of assessing caregivers' work in general within the research project.

The flexible interview beginning was summarized at the end by a short check with a prepared list of possible topics, and if one of these subjects had not been touched upon, it was offered for discussion. The guideline checklist for the interview comprised the following topics: general impression of the birth; moods/emotions/ fantasies; experience of space and time including its change; body experience; experience and perception of the obstetric team, the parturients' partners, and their yet unborn infants. The interview focused on the whole process from before the onset of labour to after delivery until the time of interview, lasted between 45 and 90 minutes and was videotaped.

The evaluation manual: The principles of the evaluation process are based on qualitative content analysis [42]-[44]. The videotaped interviews were evaluated without transcription.

This means that instead of particular words or movements having to be assessed quantitatively, the contents of the interviewees' statements had to be understood and the meta-messages distributed throughout the interview and conveyed by verbal and non-verbal communication had to be grasped. The categories of the manual were developed in three steps. First, a preliminary set of dimensions was proposed and explored for reliability between the interviews. In doing so, the dimensions were developed by the interviewer in a gradually progressing process: the scales were set up in a circular way involving three, five, and finally 10 interviews randomly chosen among the 73 videotapes from the beginning, the middle, and the end phase of the study. Second, the first rater was trained to ensure the reliability of the scales: After basic instructions, the same 10 interviews were rated by both the principal investigator and the trainee, and the results were compared. Where appropriate, corrections and additional explanations were added to the manual definitions. Then, the second graduate student rater had to undergo the same progressive training process: Both the principal investigator and the first rater double-checked their assessments with the new trainee. The wording of the manual was further redefined to ensure reliability where appropriate.

By means of such a circular process of reflection, adjustment of definitions and re-evaluation the IIO-subscales showed up and became accessible in a reliable way; the same holds true for other sub-scales described below in detail. By means of this we achieved data reduction, i.e. the second basic aspect of sound qualitative research, with the first basic aspect being the theory-based approach as outline in the introduction. The third basic aspect, the inter-rater reliability, will be presented below by means of the Intraclass correlations (ICC) for two blinded raters [42].

The manual version thus developed is used to evaluate the interviews presented in this work. The definite rating process with two new(!) raters was carried out without the principal investigator's direct supervision.

The dimension packages used in this analysis are assessed as follows:

Package A: Basic experiences (BE)—four subscales: anxiety, dominance of bodily processes (DbodP)—a dimension which so far has been only anecdotally described in the literature, but not labelled as such (see below), pain, and exhaustion. BE is the sum-score of these four subscales, assessed as peak values. Whereas exhaustion and pain do not need further explanations, some more detailed information will be given on Anxiety and DbodP:

Anxiety: In our understanding of anxiety we refer to a model in which it is generally understood as the loss of the basic "background feeling of safety" [45]. Thus, anxiety during childbirth may be a general feeling of "uncertainty" [46], but also a directed cognitive fear about various concerns, like one's infant health, or the parturient's own integrity. Furthermore, our approach is based on the notion, that anxiety can remain unconscious and be communicated indirectly, therefore, becoming apparent by various behaviours, like "nervousness", vomiting, 
easily provoked irritation, behaviour seeking external control, etc.

Dominance of bodily processes (DbodP): This new dimension has not yet been mentioned in the research literature as such (see also introduction to this paper). It is best illustrated by means of some of the women's verbatim statements and metaphorical expressions like "I felt like I was being run over by a train, and I could not escape" accompanied by the sensation of being "out of breath". Other metaphorical descriptions were "while time was flying I felt like I was running after what was happening”, or "I felt as if I was living half a year compressed into three hours". These descriptions of a dominance of bodily processes are in line with statements in another investigation [28]: “...that's the way your body functions, it's just the way you would describe a giant wave that's coming ashore and you are forced to follow the wave, and if you fight against it... it just turns worse, so I have to follow...”.

Thus, the experience of feeling overwhelmed included a certain loss of control over bodily processes, often also enhancing a change in the experience of time. The clinical importance of this new dimension was underlined by some of the women's verbatim statements that, mainly due to this experience, they had asked for an epidural anaesthesia. If this proves valid, it challenges the clinical belief that epidural blocks are mainly applied to mitigate pain intensity. Furthermore, such a dominance of bodily processes was not always qualified as intolerable, as a considerable number of women also felt "carried" or "supported by" or "linked to an inner force" in a positive and helpful way when bodily processes became dominant.

Pain and exhaustion are self-explaining qualities: remember that peak values are assessed in these four subdimensions:

The BE scale (anxiety, dominance of bodily processes, exhaustion, and pain) has a Cronbach alpha of 0.73, with subscale-to-subscale correlations ranging from 0.29 to 0.52 , and with subscale-to-scale correlations ranging from 0.71 to 0.76 . The ICC is 0.85 (see Table 1). (Please note, that this correlation matrix also reveals DbodP as sufficiently independent of the other BE-subscales and of control; likewise, see below.)

Package B: Coping (COPE) — three subscales: hopelessness versus confidence, coping with pain, and fearful control versus acceptance and letting-go, describing the capacity to cope with stress experienced during childbirth.

Table 1. Correlation matrices (Pearson's r) of packages A (Basic experiences), B (Coping), and C (Intranatal Inward Orientation).

\begin{tabular}{|c|c|c|c|c|}
\hline \multicolumn{5}{|c|}{ Package A: Basic experience (BE) } \\
\hline C’alpha: 0.73 & Anxiety & DbodP & Exhaustion & BE (ICC: 0.85) \\
\hline Anxiety & - & & & 0.76 \\
\hline DbodP & 0.49 & - & & 0.76 \\
\hline Exhaustion & 0.33 & 0.29 & - & 0.72 \\
\hline Pain & 0.29 & 0.49 & 0.52 & 0.71 \\
\hline \multicolumn{5}{|c|}{ Package B: Coping (COPE) } \\
\hline \multicolumn{2}{|c|}{ C’alpha: 0.77} & Hopelessness vs. confidence & Coping with pain & COPE (ICC: 0.81 ) \\
\hline \multicolumn{2}{|c|}{ Hopelessness vs. confidence } & --- & & 0.87 \\
\hline \multicolumn{2}{|c|}{ Coping with pain } & 0.60 & --- & 0.81 \\
\hline \multicolumn{2}{|c|}{ Fearsome control vs. acceptance/dedication } & 0.61 & 0.37 & 0.81 \\
\hline \multicolumn{5}{|c|}{ Package C: Intranatal Inward Orientation (IIO) } \\
\hline C’alpha: 0.72 & IIO-time & IIO-space & IIO-attachm & IIO (ICC: 0.83) \\
\hline IIO-time & - & & & 0.65 \\
\hline IIO-space & 0.34 & - & & 0.83 \\
\hline IIO-attachm & 0.16 & 0.49 & - & 0.72 \\
\hline IIO-communic & 0.44 & 0.51 & 0.28 & 0.74 \\
\hline
\end{tabular}

C' alpha: Cronbach's alpha = internal consistency of scale; ICC: intraclass correlation with two raters. 
The first sub-dimension, hopefulness versus confidence, covers the parturient's estimation of her own capacity to keep going until the end of delivery. The second sub-dimension, coping with pain, is how the parturient felt able to deal with the pain experience, e.g. via relaxation and breathing techniques. The third sub-dimension, fearful control versus acceptance and dedication, addresses the parturient's capacity to "let go", and hand over control to the care-giving environment and rely on her own strength. COPE is the sum score of the three subscales, assessed as mean values.

Hopelessness vs. confidence: In the lowest score, the parturient experiences almost permanently a sense of helplessness, frustration, exhaustion, guilt, giving up and being at a dead-end; in contrast the highest score is applied, if the parturient almost permanently feels her own strength, and does not experience any challenge to the confidence that "she will make it". A crucial hint for the rating of this subscale often comes from the experience of the process as "going on": thus the experience of an endlessly lasting birth process is an indirect parameter pointing towards a weakening of confidence; diffuse anger may also result from the loss of confidence and the experience of being at the verge of despair and hopelessness. Note that these experiences are rated regardless of the influence of attending or accompanying persons: In some cases, despair was elicited by inadequate informations or inappropriate behaviour from the caregivers' or the partners' side.

Coping with pain: The spectrum in this subdimension starts at complete failure of coping with pain: The parturient experiences her pain as extreme, and feels overwhelmed by the pain; she cannot manage any more to use the breathing or relaxation techniques she might have been taught in antenatal childbirth classes, or if she manages, these techniques don't relive her at all; on the other end of the spectrum coping with pain is stable and possible: The parturient perceives labour pain as strong, but tolerable; perhaps she even welcomes it in the service of labour progress, thus experiencing it as part of a useful dynamic; [in case of an epidural rate coping with pain before the onset of the epidural block is assessed].

Fearful control vs. acceptance and letting-go: In contrast to the previous subdimension where the focus is on "coping with a bodily sensation and experience, i.e. pain", in this subdimension the focus is on the "emotional aspect of coping", including possible dynamics secondary to a loss of "emotional coping".

The lower pole of this subdimension is characterized by fear, panic, worry, feeling "nervous", inner restlessness, insecurity, and even suspicion. [Note: Fear and anxiety is rated regardless of the object of fear: her child, herself, or anything or anybody else, or no specific object]. The scoring in the lower spectrum goes along two phenomenological lines. Either the line of overtly mentioned and experienced anxiety [Note: Eventually the parturient describes a certain loss of "orientation", which could be in line with anxiety, but be aware that the loss of orientation per se is not the experience which is described here, as orientation is also linked to the experience of time, which is assessed in other dimensions!], or the line of mechanisms of suppression of anxiety like a strong belief in medical techniques, strong rationalization (in the sense of defence mechanisms as used in psychodynamic theories), and an attitude of taking strong ("external”) control over the medical procedures and the caregivers' actions. Likewise the feelings of shame, or feeling "strange" and isolated or various degrees of distrust towards caregivers should be interpreted as correlates of a loss or lack of inner stability, i.e. "internal control" [Note: This occurs regardless if the caregivers' actions and attitudes have "really" to be blamed of being inadequate, or if it might be the parturient's projection: the woman's resulting or underlying state is "inner instability", which is, then, rated here]. The upper pole of this subdimension is characterized by inner calm and strength, confidence in nature, feeling safe and held, and feeling secure: The pole of confidence comprises trust in the environment (caregivers and partner), in herself, her own body, and her own process of giving birth.

The COPE scale has a Cronbach alpha of 0.77 with subscale-to-subscale correlations ranging from 0.37 to 0.61 and with subscale-to-scale correlations ranging from 0.81 to 0.87 . The ICC is 0.81 (see Table 1 ).

Package C: Intranatal Inward orientation (IIO)—four subscales: temporal experience, spatial experience, changing sense of attachment, and predominant communication style. IIO is assessed on four axes, and the observers mark "no/yes" on each if the parturient describes a coenesthetic experience. As IIO is the sum score of the four axes, values between the maximum and minimum values are also possible, indicating various degrees of IIO in the course of labour.

Temporal experience-Changing sense of time (IIO-time): A change in the sense of time dimension is assumed, when the parturient reports a loss of temporal orientation with regard to the clock-registered time. It could be the parturient reports moments of surprise when she became aware of the "real clock time" in the course of her labour process. An indication of such a change may be the parturient's inability to bring her memories into sequential order, or if she experiences "missing pieces" in her recall of the process. [Note: This 
scale does NOT assess the perceived time-speed, like "everything went so fast", or "the whole delivery lasted forever".]

Spatial experience-Changing sense of space (IIO-space): A change in the sense of space is assumed when the parturient reports a limited perceived space towards the end of the labour process. The perceived space is then limited to a sphere around the place where she is actually located, and which she could have outlined with her extended arms, like in a circle or globe. Beyond this limited space details were not perceived, and also persons outside the space were not integrated into her perception, i.e. they remained anonymous.

Changing sense of attachment (IIO-attachm): This dimension refers to the meaning of the real presence of birth-related significant others, i.e. usually of the midwife and the partner, or another labour companion. At the beginning of the birth process the parturient usually does not report a need for the continuous presence of her significant others, but reports that the certainty that they would be there whenever she needed them was sufficient. If this experience changes, a change of attachment is assumed. From a certain moment the parturient reports the experience that she could no longer tolerate a limited absence of these persons, or even the idea of their absence. Imagining their absence would cause profound emotional irritation and anxious feelings. In other words, the symbolic presence of significant others was no longer sufficient, and a "real", i.e. non-symbolic presence, was necessary to avoid emotional destabilisation. Thus, "sense of attachment", as it is used in this context, refers to the way relationship and intimacy is organized and structured, and maintained, i.e. symbolically or non-symbolically, and if a change in this organization occurs due to a parturient's changing internal needs. In other words, it is not a matter of "any attachment", but of "what kind of attachment".

Shift in predominant communication style (IIO-communic): In this dimension we basically differentiate two communication styles. First, the information seeking, visually and verbally controlling style, in which orientation is provided by cognitive thinking, and second, the emotion based style, in which orientation is provided by sound and touch, characterized by an attitude of "letting-go" and a trust in nature and the attending environment. Examples for the first communication style are discussions about procedures, their advantages and disadvantages, the interpretation of foetal monitoring, as well as the description of distracting behaviours like joking, and activities in general, and so on. Examples of the second communication style are reports of the caregivers' voices being important (in contrast to their verbal explanations, which were fast forgotten), or the meaning of careful touch (in contrast to relaxation "techniques" or examinations).

\subsection{Questionnaire-Based Measures}

1) Intranatal "peritraumatic dissociative experience" (PDE) and "peritraumatic emotional experience" (PEE), see Table 2. These two scales are derived from a principal component analysis $(n=251)$ of the unpublished

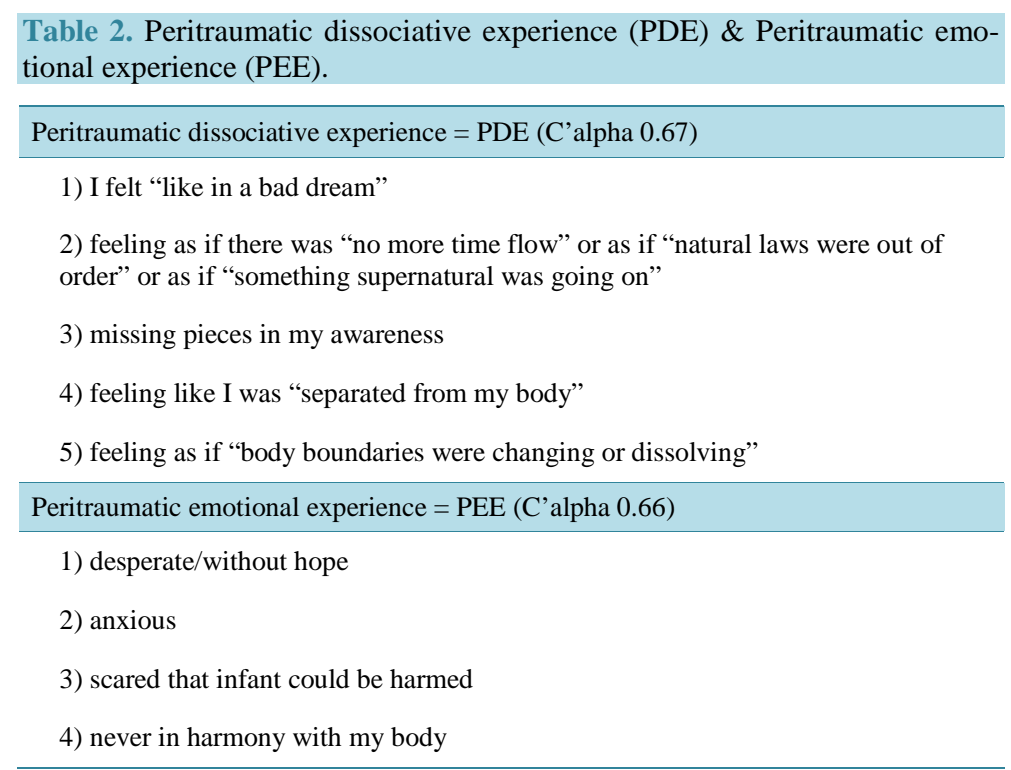

C’alpha: Cronbach's alpha = internal consistency of scale. 
32-item-questionnaire BBCI (Berne-Basle Childbirth Inventory: inter-subscale-correlation of 0.52, i.e. both have to be considered as subscales independent of each other). PDE (Cronbach Alpha $=0.67$ ) comprises five items correlating with the sum score from 0.63 to 0.67 . It is highly correlated with the PDEQ (Pearson's r: 0.65, [47]), a scale measuring peritraumatic dissociative experiences [48] in non-obstetric situations [49]. PEE (Cronbach Alpha $=0.66$ ) comprises four items correlating with the sum score from 0.59 to 0.74 .

2) Control: To assess the experience of not-in-control we use one question of the 20-item questionnaire SILGer (Salmon's Item List-German Language version [19]). Loss of control is correlated (Pearson's r) with DbodP (0.31, see above), exhaustion (0.40), pain (0.33), confidence $(-0.39)$, and coping with pain $(-0.35)$, but not with anxiety (0.11: n.s.) or acceptance/dedication ( -0.18 : n.s.). This provides good content validity for the idea of control being mostly correlated with, but sufficiently independent of, these other intranatal subjective experiences.

\subsection{Correlation Matrix of Measures Described Above}

Both BE and COPE are highly interrelated, with -0.75 . Furthermore, PEE is highly related with BE $(0.60)$ and COPE (-0.66), contrasting with PDE, which is associated with BE $(0.18)$ and COPE $(-0.31)$ only to a relatively low degree. In addition, not-in-control is related to all other dimensions to almost the same, relatively low degree: from 0.33 to 0.36 (see Table 3 ).

\section{Results}

\subsection{Psychometric Properties of Intranatal Inward Orientation (IIO-Package C)- Question 1}

The only solution with an Eigenvalue $>1$ revealed by a principal component analysis of the four subscales of package $\mathrm{C}$ comprised one factor (Eigenvalue 2.0), explaining 50.1\% of the total variance and including all of the four subscales. Loadings of the subscales on this factor are 0.63 (IIO-time), 0.80 (IIO-space), 0.63 (IIO-attachm), and 0.75 (IIO-communic) with a Cronbach alpha of 0.73 , and with subscale-to-subscale correlations ranging from 0.21 to 0.52 (only between IIO-time and IIO-attachm was no significant correlation detected). The ICC for IIO is 0.83 with two raters (Table 1 ).

\subsection{IIO Associations with Other Intranatal Subjective Experiences-Question 2}

IIO is independent of all other subjective experiences, with only one significant but weak correlation with notin-control. At IIO-subscale level this association is mainly due to IIO-time (Table 4).

\subsection{IIO Associations with Obstetric Variables-Question 3}

With regard to single obstetric variables, weak but significant IIO-correlations (continuous IIO-measure) are only detected with epidural blocks. On IIO-subscale level this association is mainly due to IIO-space and to IIO-communication. This means that the higher the IIO-score, the less frequently epidural blocks were requested (see Table 4).

To proceed, we next explored the subgroups formed by the increasing degrees of birth complication profiles

Table 3. Correlation matrix (Pearson's r) of BE (Basic experiences), COPE (Coping), control, PEE (Peritraumatic emotional experience), and PDE (Peritraumatic dissociative experience).

\begin{tabular}{ccccc}
\hline & BE & COPE & Not in Control & PEE \\
\hline COPE & $-0.75^{* *}$ & - & \\
Not in Control & $0.35^{*}$ & $-0.36^{* *}$ & $0.33^{* *}$ & - \\
PEE & $0.60^{* *}$ & $-0.66^{* *}$ & $0.33^{* *}$ & $0.52^{* *}$ \\
PDE & n.s. & $-0.31^{*}$ & \\
\hline
\end{tabular}

Correlation is significant at the 0.01 level $(2$-tailed $)={ }^{* *}$ or at the 0.05 level $(2$-tailed $)={ }^{*}$; Correlation not significant $=$ n.s. 
Table 4. Correlations (Pearson's r): IIO versus subjective experiences (BE, COPE, control, PEE, and PDE) and objective obstetric variables (epidural block, labour duration, augmentation, induction, birth weight).

\begin{tabular}{|c|c|c|c|c|c|}
\hline & IIO & IIO-time & IIO-space & IIO-attachm & IIO-communic \\
\hline \multicolumn{6}{|l|}{ Subjective Experiences } \\
\hline $\mathrm{BE}$ & n.s. & - & - & - & - \\
\hline COPE & n.s. & - & - & - & - \\
\hline Not in Control & $0.26^{*}$ & $0.35^{* *}$ & n.s. & n.s. & n.s. \\
\hline PEE & n.s. & - & - & - & - \\
\hline PDE & n.s. & - & - & - & - \\
\hline \multicolumn{6}{|l|}{ Objective Obstetric Variables } \\
\hline Epidural Block & $-0.26^{*}$ & n.s. & $-0.29^{*}$ & n.s. & $-0.41^{* *}$ \\
\hline Duration of Labour (ln) & n.s. & - & - & - & - \\
\hline Augmentation & n.s. & - & - & - & - \\
\hline Induction & n.s. & - & - & - & - \\
\hline Birth Weight & n.s. & - & - & - & - \\
\hline
\end{tabular}

Correlation is significant at the 0.01 level $(2$-tailed $)={ }^{* *}$ or at the 0.05 level $(2$-tailed $)={ }^{*}$; Correlation not significant $=$ n.s.

(see method: obstetric variables) with respect to subjective variables and the infant's birth weight: They are correlated with $\mathrm{BE}$ (rho $=0.24 ; \mathrm{p}<0.05$ ), COPE (rho $=-0.38 ; \mathrm{p}<0.01$ ), PEE (rho $=0.35 ; \mathrm{p}<0.01$ ), and IIO (rho $=-0.31 ; \mathrm{p}<0.001$ ), but neither with PDE and control nor with the infant's birth weight (see Table 5).

We, then, defined IIO as a dichotomized measure (high/low) by means of a two-cluster analysis (log-likelihood distance measure with Schwarz's Bayesian criterion) revealing two groups of IIO: "high" (72.6\%: mean 4.29, SD 0.65) and "low" (27.4\%: mean 1.72, SD 0.61). The two IIO-clusters did not differ with respect to BE, COPE, PEE and PDE, nor with respect to the infant's birth weight (t-tests). Only in labour duration was there a tendency towards longer labour durations with low IIO (10.9 +/- 11.0 vs. $16.3+/-10.1$; $=1.89 ; \mathrm{p}=0.062)$ and only in epidural blocks was there a higher percentage detectable with low IIO $\left(40.6 \%\right.$ vs. $17.1 \% ; \chi^{2}=5.01 ; \mathrm{p}=$ 0.025) (see Table 5).

Lastly, we explored the distribution of high and low IIO in the three increasing degrees of birth complication profile, presented in Figure 1: with high IIO the birth complication profile is more frequently low, and vice versa, as shown by a Mann-Whitney U-Test $(\mathrm{U}=328.0, \mathrm{Z}=-2.68$; $\mathrm{p}=0.007)$.

\section{Discussion}

The present study focuses on understanding intranatal psychosomatic processes in the parturient. However, going beyond traditional approaches, which tend to look at single isolated parameters like anxiety, dominance of bodily processes, exhaustion, pain, control, peritraumatic emotions and dissociation, or coping dynamics, our work is based on the idea that it is not these isolated variables per se that are of primary significance, but an underlying shift in the mode of experience, which affects or "colours" the ongoing experience in a particular way. This is the first time that such a mode shift has been studied systematically, although certain shifts, such as a changing sense of time or space and intranatal behavioural adaptations, have been described anecdotally.

Referring to models proposed by Molinski [3], Stauber [4] and Spitz [5], we postulated that we could operationalize IIO on four axes of intranatal development, i.e. a changing sense of time and space as well as a shift in the need for immediate contact and in the predominant communication style. Our results provide statistical evidence supporting the hypothesis that IIO can be assessed in a systematic and replicable way (demonstrated by the "one-factor solution" in the principal component analysis as the only solution with an Eigenvalue > 1). Furthermore, we analysed the statistical correlations between intranatal experiences known to be of significance for women in labour, such as anxiety, pain, peritraumatic emotions, and coping dynamics and IIO. Only few and 
Table 5. Association between subjective experiences and obstetric variables versus subgroups defined by 1 ) birth complication profile and 2) high or low IIO (dichotomized measure).

\begin{tabular}{ccc}
\hline & $\begin{array}{c}\text { Birth complication profile } \\
\text { (low-moderate-high) } \\
\text { Spearman's rho }\end{array}$ & $\begin{array}{c}\text { IIO } \\
\text { (dichotomized: high-low) } \\
\text { t-test or Chi-square-test }\end{array}$ \\
\hline BE & $0.24(\mathrm{p}<0.05)$ & n.s. (1) \\
COPE & $-0.38(\mathrm{p}<0.01)$ & n.s. (1) \\
not in control & n.s. & n.s. (1) \\
PEE & 0.35 ( $<<0.01)$ & n.s. (1) \\
PDE & n.s. & n.s. (1) \\
Epidural block & n.a. & $\chi^{2}=5.01$ ( $\left.=0.025\right)(2)$ \\
IIO (continuous measure) & -0.31 (p $<0.001)$ & n.a. \\
Duration of labour (ln) & n.a. & n.s. (1) \\
Augmentation & n.a. & n.s. (2) \\
Induction & n.s. & n.s. (2) \\
Birth weight & n.s. & n.s. (1)
\end{tabular}

n.s. = not significant; n.a. = not applicable; $(1)$ = t-test; $(2)$ = Chi-square-test.

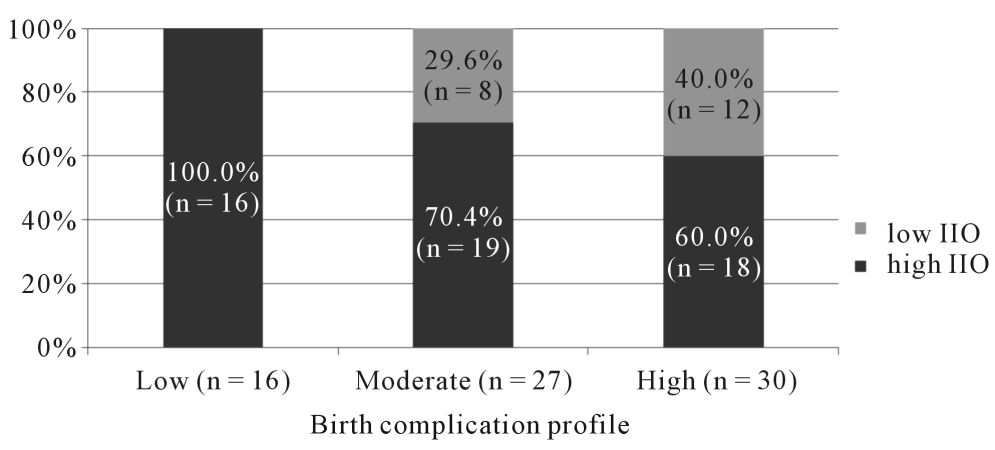

Figure 1. IIO versus birth complication profile*. Comment: With high IIO the birth complication profile is more frequently low: Mann-Whitney U-test ( $\mathrm{U}=$ 328.0, $\mathrm{Z}=-2.68 ; \mathrm{p}=0.007)$. * Legend-birth complication profile: low = no augmentation, spontaneous, no epidural block, labour $<12$ h (n = 16/21.9\%); moderate $=$ spontaneous, no epidural block, labour $>12$ h OR vag.-assisted and/or epidural block, labour $<12 \mathrm{~h}(\mathrm{n}=27 / 37.0 \%)$; high = vag.-assisted and/or epidural block, labour $>12$ h OR unplanned caesarean section ( $\mathrm{n}=$ $30 / 41.1 \%)$.

low-level associations were revealed, thus supporting our hypothesis that IIO is an intranatal dynamic on its own. From a theoretical perspective we construe independently acting IIO as a dynamic working on a meta-level, integrating instead of substituting for the other intranatal experiences.

After confirming IIO as an independent "player" in psychological intranatal processes we tested our hypothesis on IIO as a psychosomatic actor possibly promoting uneventful childbirth processes. Our analysis showed that singling out particular parameters, like augmentation, induction, epidural blocks, mode of delivery, and duration measures, does not provide associations with IIO (with the exception of epidural blocks, which are correlated with lower IIO). However, the most striking result was the finding that all women with the lowest complication profile, described by “no augmentation, no epidural block, labour $<12$ h, and spontaneous delivery” also reported high IIO. This finding, as well as the significantly lower percentage of high IIO in the medium and high complication profile, supports our hypothesis that IIO also has effects on somatic aspects of the birthing process. 


\section{Weaknesses and Limitations of Our Study Approach and Findings}

The fact that all women were interviewed by the same male, well-trained and clinically experienced researcher is a strength in our design with regard to the consistency of data assessment. However, it remains unclear how the gender-aspect may have biased the women's answers and behaviour in the interview. This question needs further research by randomly assigning high quality interviewers of both genders.

Another aspect concerns the direction of the effect, i.e. whether IIO supports less complicated childbirth, or whether uneventful childbirth induces IIO, our data provides only limited answers. However, the finding that IIO is not correlated with the infant's birth weight goes against the idea that mechanically easy deliveries may induce IIO. As two IIO-subscales comprise aspects of social support, our findings are in line with Klaus [50] who found that higher social support during labour was associated with less maternal and infant morbidity.

Although IIO is a promising model that helps to understand various intranatal dynamics from a common perspective, its conceptualisation must still be considered preliminary. In particular, the finding that IIO is also present in complicated deliveries, yet to a lesser extent compared to uneventful deliveries, cannot be explained by our research. We assume that among factors contributing to a better understanding of the interplay between IIO and the somatic birth process could be the perceived intranatal support from caregivers, a protective factor in immediate postpartum maternal well-being [51], as well as the intranatal relationship with the partner. Moreover, further elaborations on the concept need to take aspects of personality into account.

The concept of IIO delineates stressful intra-partum dynamics, which are potentially helpful and supportive in promoting uneventful birthing processes. This places our work in the context of the large body of psychosomatic literature elaborating on the differentiation of eustress and distress. Normal childbirth, as a natural body-related process in a woman's life, is stressful in the sense of eustress, and some of its stress equivalents, like loss of control and body-related stress experiences, form part of the healthy, birth-promoting dynamic of intranatal inward orientation (IIO). Therefore, in an obstetric approach supporting normal childbirth, the clinical attendance of childbirth cannot primarily aim at avoiding eustress in normal childbirth, but at finding ways that allow the parturient to enter the process of IIO without developing distress. Dissociative phenomena may serve as an example to shed light to the clinical dilemma: we showed them to be part of IIO, a stressful dynamic in the sense of eustress. However, the very same dissociative phenomena have also been revealed to be markers of a peritraumatic childbirth experience, i.e. an experience in the sense of distress. Yet, no diagnostic tools have so far been developed to distinguish normative (eustress-related) from pathological (distress-related) dissociative experiences. Furthermore, the research on maternal traumatic birth experiences has had the tendency to single out certain stressful parameters like pain, control, and obstetric interventions, which are then correlated with a traumatic birth experience. Yet, the question of why and how the vast majority of women who have experienced high levels of stress during the process of giving birth have managed to keep it an experience of eustress, without being traumatized has not been addressed appropriately. Our results point to the necessity of integrating normative stress variables, i.e. markers of eustress, and peritraumatic stress variables, i.e. markers of distress, in the conceptual planning of studies on trauma in childbirth.

The model of IIO theorizing about eustress in labour is not yet applicable to clinical work. In order to further elaborate on the innovative aspects of this concept, future research should focus on a better understanding of the stepwise changes in the course of delivery, including other relationship and personality aspects. In addition, it would be desirable to further explore IIO in the context of neuro-endocrine-vegetative parameters like endorphins and cortisol. Furthermore, given its highly demanding assessment, it would be worthwhile to develop a more practicable assessment tool.

\section{Acknowledgements}

This study was conducted within a research project called "Birth experience and psycho-physical adaptation postpartum”, supported by the Swiss National Foundation (SNF-No 3200-049741.96). The evaluation process was partially done within "NCCR sesam L: Triadic family functioning - an integrated psychosomatic approach to obstetrics and infant development" (SNF-No 105314_127121) and sponsored by the private foundations Mütterhilfe and Florindon, Zürich.

The study was run as a cooperative project between the Department of Obstetrics and Gynaecology, University Hospital, Basel (Head of Department: Prof. Dr. Dr. W. Holzgreve), and The Clinic for Child and Adolescent Psychiatry, University Hospital, Basel (Head of Dept.: Prof. Dr. D. Bürgin), Switzerland. Within the Department 
of Obstetrics and Gynaecology, two units were involved: Obstetrics (Prof. Dr. I. Hösli), and Gynaecological Social Medicine and Psychosomatics (Prof. Dr. J. Bitzer).

\section{Competing Interest Statement}

The authors have no competing interests to report.

\section{References}

[1] Bewley, S.C.J. (2002) The Unfacts of “Request” Caesarean Section. British Journal of Obstetrics and Gynaecology, 109, 597-605. http://dx.doi.org/10.1111/j.1471-0528.2002.07106.x

[2] Rich, O. (1973) Temporal and Spatial Experience as Reflected in the Verbalizatons of Multiparous Women during Labor. Maternal-Child Nursing Journal, 2, 239-325.

[3] Molinski, H. (1989) Emotionale und interpersonale Aspekte der Geburt [Emotional and interpersonal aspects of labor]. Der Gynakologe, 22, 96-99.

[4] Stauber, M. (1996) Geburtshilfe [Obstetrics]. In: Uexküll, T.V., Ed., Psychosomatische Medizin [Psychosomatic Medicine], Urban \& Schwarzenberg, München, Wien, Baltimore, 1046-1056.

[5] Spitz, R.A. (1945) Diacritic and Coenesthetic Organizations. Psychoanal Review, 32, 146-162.

[6] Bernstein, E.M. and Putnam, F.W. (1986) Development, Reliability, and Validity of a Dissociation Scale. The Journal of Nervous and Mental Disease, 174, 727-735. http://dx.doi.org/10.1097/00005053-198612000-00004

[7] Putnam, F.W. (1989) Pierre Janet and Modern Views of Dissociation. Journal of Traumatic Stress, 2, 413-429. http://dx.doi.org/10.1002/jts.2490020406

[8] Waller, N., Putnam, F.W. and Carlson, E.B. (1996) Types of Dissociation and Dissociative Types: A Taxometric Analysis of Dissociative Experiences. Psychological Methods, 1, 300-321. http://dx.doi.org/10.1037/1082-989X.1.3.300

[9] Beck, C.T. (1994) Women’s Temporal Experiences during the Delivery Process: A Phenomenological Study. International Journal of Nursing Studies, 31, 245-252. http://dx.doi.org/10.1016/0020-7489(94)90050-7

[10] Beck, C.T. (1983) Parturients' Temporal Experiences during the Phases of Labor. Western Journal of Nursing Research [Comparative Study], 5, 283-300.

[11] Birch, E.R. (1986) The Experience of Touch Received during Labor. Postpartum Perceptions of Therapeutic Value. Journal of Nurse-Midwifery, 31, 270-275.

[12] McKay, S. and Roberts, J. (1990) Obstetrics by Ear-Maternal and Caregiver Perceptions of the Meaning of Maternal Sounds during Second Stage Labor. Journal of Nurse-Midwifery, 35, 266-273. http://dx.doi.org/10.1016/0091-2182(90)90079-K

[13] McKay, S. (1993) What Are They Talking About? Is Something Wrong? Information Sharing during the Second Stage of Labor. Birth, 20, 142-147. http://dx.doi.org/10.1111/j.1523-536X.1993.tb00439.x

[14] McIntosh, J. (1988) Women's Views of Communication during Labour and Delivery. Midwifery, 4, 166-170. http://dx.doi.org/10.1016/S0266-6138(88)80072-X

[15] Melzack, R. (1984) The Myth of Painless Childbirth (the John J. Bonica Lecture). Pain [Research Support, Non-US Gov't Review], 19, 321-337.

[16] Lowe, N.K. (1996) The Pain and Discomfort of Labor and Birth. Journal of Obstetric, Gynecologic, \& Neonatal Nursing, 25, 82-92. http://dx.doi.org/10.1111/j.1552-6909.1996.tb02517.x

[17] Lowe, N.K. (2002) The Nature of Labor Pain. American Journal of Obstetrics \& Gynecology, 186, S16-S24. http://dx.doi.org/10.1016/S0002-9378(02)70179-8

[18] Salmon, P. and Drew, N.C. (1992) Multidimensional Assessment of Women's Experience of Childbirth: Relationship to Obstetric Procedure, Antenatal Preparation and Obstetric History. Journal of Psychosomatic Research, 36, 317-327. http://dx.doi.org/10.1016/0022-3999(92)90068-D

[19] Stadlmayr, W., Bitzer, J., Hosli, I., Amsler, F., Leupold, J., Schwendke-Kliem, A., Simoni, H. and Burgin, D. (2001) Birth as a Multidimensional Experience: Comparison of the English- and German-Language Versions of Salmon's Item List. Journal of Psychosomatic Obstetrics and Gynaecology, 22, 205-214.

[20] Waldenstrom, U. (1999) Experience of Labor and Birth in 1111 Women. Journal of Psychosomatic Research, 47, 471482. http://dx.doi.org/10.1016/S0022-3999(99)00043-4

[21] Alehagen, S., Wijma, B. and Wijma, K. (2001) Fear during Labor. Acta Obtsetrica et Gynecologica Scandinavica, 80, 315-320.

[22] Niven, C. and Gijsbers, K. (1984) A Study of Labour Pain Using the MCGILL Pain Questionnaire. Social Science \& 
Medicine, 19, 1347-1351. http://dx.doi.org/10.1016/0277-9536(84)90023-6

[23] Lederman, R.P., Lederman, E., Work, B. and McCann, D. (1985) Anxiety and Epinephrine in Multiparous Women in Labor: Relationship to Duration of Labor and Fetal Heart Rate Pattern. American Journal of Obstetrics \& Gynecology, 153, 870-877. http://dx.doi.org/10.1016/0002-9378(85)90692-1

[24] Lowe, N.K. (1987) Individual Variation in Childbirth Pain. Journal of Psychosomatic Obstetrics \& Gynecology, 7, 183-192. http://dx.doi.org/10.3109/01674828709040278

[25] Lowe, N.K. (1992) Differences in First and Second Stage Labor Pain between Nulliparous and Multiparous Women. Journal of Psychosomatic Obstetrics \& Gynecology, 13, 245-253. http://dx.doi.org/10.3109/01674829209009197

[26] Brown, S.T., Campbell, D. and Kurtz, A. (1989) Characteristics of Labor Pain at Two Stages of Cervical Dilation. Pain, 38, 289-295. http://dx.doi.org/10.1016/0304-3959(89)90215-7

[27] Ranta, P., Jouppila, P. and Jouppila, R. (1996) The Intensity of Labor Pain in Grand Multiparas. Acta Obstetricia et Gynecologica Scandinavica, 75, 250-254.

[28] Lundgren, I. and Dahlberg, K. (1998) Women’s Experience of Pain during Childbirth. Midwifery, 14, 105-110. http://dx.doi.org/10.1016/S0266-6138(98)90007-9

[29] Green, J.M. and Baston, H.A. (2003) Feeling in Control during Labor: Concepts, Correlates, and Consequences. Birth, 30, 235-247.

[30] Waldenström, U., Borg, I.M., Olsson, B., Sköld, M. and Wall, S. (1996) The Childbirth Experience: A Study of 295 New Mothers. Birth, 23, 144-153. http://dx.doi.org/10.1111/j.1523-536X.1996.tb00475.X

[31] Mould, T.A.J., Chong, S., Spencer, J.A.D. and Gallivan, S. (1996) Women’s Involvement with the Decision Preceding Their Caesarean Section and Their Degree of Satisfaction. BJOG: An International Journal of Obstetrics \& Gynaecology, 103, 1074-1077. http://dx.doi.org/10.1111/j.1471-0528.1996.tb09585.x

[32] Niven, C.A. and Gijsbers, K. (1996) Coping with Labor Pain. Journal of Pain and Symptom Management, 11, 116-125.

[33] Lowe, N.K. (1989) Explaining the Pain of Active Labor: The Importance of Maternal Confidence. Research in Nursing \& Health, 12, 237-245. http://dx.doi.org/10.1002/nur.4770120406

[34] Lowe, N.K. (2000) Self-Efficacy for Labor and Childbirth Fears in Nulliparous Pregnant Women. Journal of Psychosomatic Obstetrics and Gynaecology, 21, 219-224.

[35] Wuitchik, M., Bakal, D. and Lipshitz, J. (1989) The Clinical Significance of Pain and Cognitive Activity in Latent Labor. Obstetrics \& Gynecology, 73, 35-42.

[36] Wuitchik, M., Bakal, D. and Lipshitz, J. (1990) Relationships between Pain, Cognitive Activity and Epidural Analgesia during Labor. Pain, 41, 125-132. http://dx.doi.org/10.1016/0304-3959(90)90016-7

[37] Chapman, C.R. and Gavrin, J. (1993) Suffering and Its Relationship to Pain. Journal of Palliative Care, 9, 5-13.

[38] Derogatis, L.R. (1977) SCL-90-R, Administration, Scoring \& Procedures Manual—I for the R(evised) Version. John Hopkins University School of Medicine, Baltimore.

[39] Franke, G.H. (1995) SCL-90-R: Die Symptom-Checkliste von Derogatis. Deutsche Version [SCL-90-R. The Symptom-Checklist of Derogatis. German Version]. Beltz, Göttingen.

[40] Anastasi, A. (1976) Fundamentals of Biostatistics. 4th Edition, Macmillan, New York.

[41] Rosner, B. (1995) Fundamentals of Biostatistics. 4th Edition, Wadsworth Publishing Company, Belmont.

[42] Mayring, P. (1995) Qualitative Inhaltsanalyse. Grundlagen und Techniken [Qualitative Content Analysis. Basics and Te-chniques]. 5th Edition, Beltz, Weinheim-Basel.

[43] Pope, C. and Campbell, R. (2001) Qualitative Research in Obstetrics and Gynaecology. British Journal of Obstetrics and Gynaecology, 108, 233-237. http://dx.doi.org/10.1016/S0306-5456(00)00077-2

[44] Patton, M.Q. (2002) Qualitative Research \& Evaluation Methods. Sage, Thousand Oaks, London, New Delhi.

[45] Sandler, J. (1960) The Background of Safety. The International Journal of Psychoanalysis, 41, 352-356.

[46] Stainton, M.C., Harvey, S. and McNeil, D. (1995) Understanding Uncertain Motherhood. A Phenomenological Study of Women in High-Risk Perinatal Situations. Faculty of Nursing, University of Calgary, Calgary.

[47] Stadlmayr, W., Bitzer, J., Amsler, F., Simoni, H., Alder, J., Surbek, D. and Burgin, D. (2007) Acute Stress Reactions in the First 3 Weeks Postpartum: A Study of 219 Parturients. European Journal of Obstetrics \& Gynecology, 135, 65-72.

[48] Marmar, C.R., Weiss, D.S. and Metzler, T.J. (1997) The Peritraumatic Dissociative Experiences Questionnaire. In: Wilson, P. and Keane, T., Eds., Assessing Psychological Trauma and PTSD, Guilford Press, New York and London, 412-428.

[49] Marmar, C.R., Weiss, D.S., Schlenger, W.E., Fairbank, J.A., Jordan, B.K., Kulka, R.A. and Hough, R.L. (1994) Peritraumatic Dissociation and Posttraumatic Stress in Male Vietnam Theater Veterans. American Journal of Psychiatry, 
151, 902-907.

[50] Klaus, M.H. (1986) Effects of Social Support during Parturition on Maternal and Infant Morbidity. British Medical Journal, 293, 585-587.

[51] Gürber, S., Bielinski-Blattmann, D., Lemola, S., Jaussi, C., von Wyl, A., Surbek, D., Grob, A. and Stadlmayr, W. (2012) Maternal Mental Health in the First 3-Week Postpartum: The Impact of Caregiver Support and the Subjective Experience of Childbirth-A Longitudinal Path Model. Journal of Psychosomatic Obstetrics and Gynaecology, 33, 176-184. 